\title{
Perception of In-Service Teachers Towards Blended Learning as the New Normal in Teaching-Learning Process Post COVID-19 Pandemic
}

Dr. Rabiya Saboowala ( $\sim$ sairazsaboowala@gmail.com )

Independent Researcher https://orcid.org/0000-0002-0008-5599

Dr. Pooja Manghirmalani-Mishra

University of Mumbai- Institute of Distance and Open Learning

\section{Research Article}

Keywords: Blended Learning, COVID-19, Teaching-Learning, Education 4.0

Posted Date: August 12th, 2020

DOI: https://doi.org/10.21203/rs.3.rs-56794/v1

License: (c) (1) This work is licensed under a Creative Commons Attribution 4.0 International License.

Read Full License 


\section{Abstract}

Blended learning is the application of Information and Communication Technology in the instructional designs and processes in such a way that it can support and complement face-to-face delivery models effectively. It offers the teachers and the students to get access to information-rich resources anywhere and anytime. It also has the potential to ensure educational equity for all learners with complete transparency of rendering education to the community of learners. Today, blended learning has become the need of the hour looking into the aspects of global pandemic of COVID-19 and implementation of Education 4.0. The study consists of 313 in-service teachers from India belonging to various types of Educational Institutions. Simple random technique of sampling was used to collect data. The interaction effect of gender and teachers who have attended/conducted webinars/ workshops/ conferences/FDPs online or not on their attitude towards blended learning and its six dimensions viz. learning flexibility, online learning, study management, technology, classroom learning and online interaction was studied. Also, the interaction between the effects of highest educational qualification of teachers and teachers who have attended/conducted webinars/workshops/conferences/FDPs online or not on their attitude towards Blended Learning and its six dimensions was considered. Analysis for the testing research hypothesis was done using the IBM Statistical Package for Social Scientists (SPSS-26). The results indicated that there was an interaction between gender and teachers who have or have not conducted/attended webinars/conferences online towards blended learning and online learning dimension. Results also showed that based on the interaction effect of the highest qualification of the teacher and the teachers who have actually implemented teaching and learning through online line sessions varied in their attitude as far as study management and classroom environment was considered. Implementation of blended learning for professional growth of school teachers post pandemic will push the boundaries of learning by creating opportunities for collaboration of various educational societies throughout the globe, enhance constructivist learning and also help in following social norms set to fight against COVID-19.

\section{Introduction}

The state of the country has changed a lot in the past 100 years. With a global acceptance of Education 4.0, non-traditional methods of teaching-learning are encouraged. Apart from this, the pandemic of COVID-19 which has hit the world with increasing severity since January 2020 has flipped the global education system. The impact of COVID-19 has been tremendous on the education sector (ILO, 2020). The face-to-face learning has moved to online learning completely which is in-line with the proposition of Education 4.0. Education 4.0 is a response to the needs of Industrial Revolution 4.0 where human and technology are aligned to enable new possibilities (Hussin A.A., 2018). Education 4.0 states that Learning is built around the learner as to where and how to learn and tracking of their performance is done at every stage (Fisk, 2017). Education 4.0 promotes e-Learning tools as they offer great opportunities for remote, 
self-paced learning. Flipped classroom approach also plays a huge role as it allows interactive learning to be done in class, while the theoretical parts can be learned outside the class time.

Blended learning is one such approach which inculcates online and offline mode of learning. It is a methodology that has been introduced over a decade ago which is used in the field of education that combines (or blends) online learning with traditional place-based classroom methods (face-to-face learning). Friesen (2016) found that, in the early days of blended learning, the term could mean almost any combination of technologies, pedagogies and even job tasks. Procter (2016) defined blended learning in 2003 as 'the effective combination of different modes of delivery, models of teaching and styles of learning'. During this critical time, the Government of India has come up with the National Education Policy 2020 which addresses the crucial matters of critical and innovative thinking, philosophy of education, purpose of education along with many more points. This policy also encourages Blended Mode of learning (MHRD's NEP, 2020) as one of the potential building blocks to make India the global powerhouse for education.

Since blended learning is being adopted by educational institutions all over the globe, there is an urgent need to examine the readiness and willingness on part of the stakeholders in implementing this technology aided learning. Further, it is also necessary to estimate the capability of stakeholders in designing and implementing blended learning courses which incorporate effective pedagogy. This study highlights the attitude of Indian teachers and educational administrators to adapt the blended mode of learning along with certain key parameters which have been the base of this attitude. This study is conducted on teachers of schools (K-12), higher educational institutions, teacher educators and educational administrators.

\section{BACKGROUND}

Many studies have proved that blended learning has significant results in terms of delivery of programmes and learning-outcomes. Most studies under consideration point out that learning is enhanced through blended mode. Some prominent studies are mentioned in this background of blended learning.

Dzuiban, Hartman \& Moskal (2004) described blended learning as a method that has proved to be not only effective in terms of learning outcomes, but ranks high in ratings of satisfaction with students as well as the instructors. Sharpe R. (2006) explored that the students make regular and frequent use of electronic resources with few reported problems to access, and particularly they value flexible access both from home and campus.

Yoko H. et al (2008) acknowledged that most of the students preferred the online learning to the traditional classes and they felt that the combination of online learning and face-to-face learning was advantageous for learners. Further, blended learning allows for a range of teaching and learning practices 
to be combined for a customized learning experience even for diverse learning needs and different formats. Simon S. et.al (2008) developed a multimedia online learning resource for medical students specifically designed to support problem-based learning sessions and to enhance student-engagement and to promote clinical reasoning. The online courses so delivered resulted in much greater access to and use of educational materials than in previous years. Further, the study concluded that the blended learning facilitated delivery of the common contents, so developed, at geographically distant sites and helped to engage students in interactive project-based learning seminars.

Tolks D. et.al (2014) reached similar conclusions in the study in which they developed a blended learning course following the Inverted Classroom Model as a part of the faculty development curriculum. The course proved to be successful and was accepted during the first phase of implementation by the participants.

The above studies have revealed that blended learning has been successful in effective delivery of instructional contents and it has achieved the expected learning outcomes for the different academic disciplines and subdisciplines.

Kaur K. et al (2004), conducted a study on assessing the e-readiness for online learning among learners and tutors at an Open University. The study explored that there is a greater degree of e-readiness in comparison to academic and cultural acceptance. It was also identified that there exists a high level of preference among learners and tutors towards non-electronic channels of communication and modes of learning in comparison to learning through e-networks.

Popovich et al (2005) examined the increasing importance of delivering education via internet for business schools are consistent with the broader trends in higher education whereas Balraj K. (2011) made a study for management graduates in which he pointed out that most of the students at Graduate School of Business preferred a blend with a bias towards face-to-face delivery, and the institutions should consider profile and preferences of learners before designing and implementing programmes in blended mode.

Hwang and Arbaugh (2006) examined student feedback seeking behavior of the students enrolled in seven blended undergraduate HR and management courses. They assessed that the students who seek positive behaviour tended to participate more actively in discussion forums and seek feedback both inside and outside of class meetings, whereas students having negative feedback-seeking behaviour tended to seek instructions outside of classroom and participate in more discussion forums but with less intensity.

Raturi R. et al (2011) found that the learners in their sample were keen and enthusiastic about the use of technology. The study revealed that the group was found to be technology. The study also found a high level of digital awareness among female learners and their good access to tools; technology and experience make them capable of studying in blended-learning or e-learning mode. The cohort mentioned 
in the study indicated its readiness for e-learning, and indicated the emergence of e-learning as a preferred mode of delivery for postgraduate students.

In a nutshell, perusal of the studies revealed that a large number of researches have been conducted on blended learning, but no study actually talks about the readiness of the teachers themselves. Teachers are suddenly told to adapt in this form of teaching due to COVID-19. Most of the educational institutions had to shut down suddenly in the month of March 2020 and hence face to face orientation of teachers on e-learning has not been conducted. Most of the institutions were unable to provide any technical assistance to their teachers. This study hence considers these parameters to understand the readiness of teachers to adapt to blended forms of learning. Parameters like gender, hands on experience to learn and teach online and the highest qualification of the teachers makes a difference in the attitude of the teacher to adapt to the blended form of learning.

\section{Methods}

\section{RESEARCH METHODOLOGY, SAMPLING AND TOOLS}

The present study adopted a descriptive survey method. The sample was selected by simple random technique by circulating google forms in order to collect data due to the COVID-19 pandemic. The total sample consisted of 313 in-service teachers teaching in various educational institutes like schools, colleges, teacher education institutes, management schools, law colleges, etc all over India. The questionnaire for the present study was adapted from Birbal et al. (2018) study on learners' readiness for blended learning. The instrument consisted of 34 items that measured learners' attitudes towards six different dimensions of blended learning: learning flexibility (4 items); online learning ( 8 items); study management ( 6 items); technology (4 items); classroom learning (5 items) and online interaction (7 items). Learning flexibility reflected issues such as access to learning materials and freedom to decide where and when to study and at what pace. Online learning included items on how comfortable teachers felt about self-directed learning. Study management referred to how motivated teachers are to organize their time when studying on-line for their courses. Technology consisted of items that reflected teachers' familiarity with digital technologies and software. Online interaction refers to teachers' ability to use web technologies to collaborate with other members of the learning community for assignments and to interact with the lecturer. Classroom learning focused on teachers' preferences for face-to-face interaction with other teachers and the lecturer during training programs and conferences, seminars or symposiums. The table below represents the sample size of the present study in percentage. The sample for the present study was classified as per age, gender, medium of instruction of the educational institutes where the teachers are working, highest educational qualification of teachers and if the teachers have attended/conducted webinars/workshops/conferences/FDPs online or not during the pandemic era. Highest educational qualification of teachers was divided into three major categories viz. graduate, postgraduate and Ph.D. /M.Phil.

\section{Table 1: Sample Size for the Present Study}




\begin{tabular}{|c|c|c|c|}
\hline Variables for the study & & $\mathbf{N}$ & Percentage \\
\hline \multirow{2}{*}{ Gender } & Female & 221 & 70.61 \\
\cline { 2 - 4 } & Male & 92 & 29.39 \\
\hline \multirow{2}{*}{ Webinar/ Conferences/ Workshops/ FDPs } & No & 25 & 7.99 \\
\cline { 2 - 4 } & Yes & 288 & 92.01 \\
\hline \multirow{2}{*}{ Highest Qualification } & Ph.D. / M.Phil. & 91 & 29.08 \\
\cline { 2 - 4 } & Graduate & 54 & 17.25 \\
\cline { 2 - 4 } & Post Graduate & 168 & 53.67 \\
\hline
\end{tabular}

The figures 1, 2 and 3 represent a pie chart of sample size of the present study based on gender, teachers who have conducted/ attended Webinars/workshops/conferences/FDPs online or not during COVID-19 Pandemic and their highest educational qualifications respectively. Out of 313 teachers $70.61 \%$ were females and $29.39 \%$ were males. $17.25 \%$ teachers were graduates, $53.67 \%$ were post-graduates and $29.08 \%$ teachers hold a Ph.D. or M. Phil. Degree. 92.01\% in-service teachers have either conducted or attended webinars/ workshops/ conferences/ FDPs online during the pandemic era and $7.99 \%$ have not.

\section{HYPOTHESIS TESTING AND INTERPRETATION:}

The following null hypotheses were framed for the present study. Relevant descriptive and two-way ANOVA was done in order to understand the interaction effect using Statistical Package for Social Scientists (SPSS-26) for hypothesis testing.

1. There is no significant interaction effect between gender and teachers who have or have not conducted/attended webinars/conferences online on their attitude towards blended learning and its following dimensions:

- Online Learning

- Classroom Learning

- Online interaction

- Technology

- Learning Flexibility

- Online Environment

Table 2: Two-way ANOVA for interaction effect of gender and teachers who have conducted/attended webinars/workshops/conferences/FDPs online or not during COVID-19 era on BL and its 


\begin{tabular}{|c|c|c|c|c|}
\hline & Variables & Mean Square & F & Sig. \\
\hline \multirow{3}{*}{ BL } & Gender & 1965.081 & 2.513 & .114 \\
\cline { 2 - 5 } & webinars/workshops/conferences/FDPs online & 2474.074 & 3.164 & .076 \\
\cline { 2 - 5 } & Gender*webinars/workshops/conferences/FDPs online & 3051.819 & 3.902 & .049 \\
\hline \multirow{4}{*}{ F1 } & Gender & 28.547 & 1.557 & .213 \\
\cline { 2 - 5 } & webinars/workshops/conferences/FDPs online & 41.453 & 2.260 & .134 \\
\cline { 2 - 5 } & Gender*webinars/workshops/conferences/FDPs online & 15.648 & .853 & .356 \\
\hline F2 & Gender & 128.882 & 2.239 & .136 \\
\cline { 2 - 5 } & webinars/workshops/conferences/FDPs online & 417.508 & 7.253 & .007 \\
\cline { 2 - 5 } & Gender*webinars/workshops/conferences/FDPs online & 432.849 & 7.520 & .006 \\
\hline F3 & Gender & 11.870 & .668 & .414 \\
\cline { 2 - 5 } & webinars/workshops/conferences/FDPs online & 28.852 & 1.625 & .203 \\
\cline { 2 - 5 } & Gender*webinars/workshops/conferences/FDPs online & 46.538 & 2.621 & .107 \\
\hline F4 & Gender & 43.601 & 2.539 & .112 \\
\cline { 2 - 5 } & webinars/workshops/conferences/FDPs online & 37.535 & 2.185 & .140 \\
\cline { 2 - 5 } & Gender*webinars/workshops/conferences/FDPs online & 48.405 & 2.818 & .094 \\
\hline F5 & Gender & 87.414 & 3.395 & .066 \\
\cline { 2 - 5 } & webinars/workshops/conferences/FDPs online & 2.569 & .100 & .752 \\
\cline { 2 - 5 } & Gender*webinars/workshops/conferences/FDPs online & 40.219 & 1.562 & .212 \\
\hline F6 & Gender & 67.828 & 1.159 & .282 \\
\cline { 2 - 5 } & webinars/workshops/conferences/FDPs online & 95.409 & 1.631 & .203 \\
\cline { 2 - 5 } & Gender*webinars/workshops/conferences/FDPs online & 107.359 & 1.835 & .177 \\
\hline
\end{tabular}

(BL= Blended Learning, F1= Learning Flexibility, F2= Online Learning, F3= Study Management, F4= Technology, F5= Classroom Learning and F6= Online Interaction)

A two-way ANOVA was conducted that examined the effect of gender and teachers who have attended/conducted webinars/workshops/conferences/FDPs online or not during COVID-19 pandemic on their attitude towards blended learning and its six dimensions as an approach for teaching-learning postpandemic. There was a statistically significant interaction between the effects of gender and teachers who have attended/conducted webinars/workshops/conferences/FDPs online or not on their attitude towards blended learning, $F=3.902, p=.049$. The plot of the mean "attitude towards of blended learning" score for each combination of groups of "Gender" and "teachers who have conducted/attended webinars/workshops/conferences/FDPs online or not " are plotted in a line graph, as shown below in figure 4 .

Also, a significant interaction was found between the effects of gender and teachers who have attended/conducted webinars/workshops/conferences/FDPs online or not on their attitude towards online learning dimension of blended learning, $F=7.520, p=.006$. The plot of the mean "attitude towards online learning dimension of blended learning" score for each combination of groups of "Gender" and " teachers who have conducted/attended webinars/workshops/conferences/FDPs online or not " are plotted in a line graph, as shown below in figure 5 .

1. There is no significant interaction effect between highest educational qualification of teachers and teachers who have or have not conducted/attended webinars/conferences online on their attitude towards blended learning and its following dimensions: 
- Online Learning

- Classroom Learning

- Online interaction

- Technology

- Learning Flexibility

- Online Environment

Table 3: Two-way ANOVA for interaction effect of highest educational qualification of teachers and teachers who have conducted/attended webinars/workshops/conferences/FDPs online or not during COVID-19 era on BL and its Dimensions

\begin{tabular}{|c|c|c|c|c|}
\hline & Variables & $\begin{array}{c}\text { Mean } \\
\text { Square }\end{array}$ & $\mathrm{F}$ & Sig. \\
\hline \multirow{3}{*}{ BL } & Highest Educational Qualification & 2921.014 & 3.753 & .025 \\
\hline & webinars/workshops/conferences/FDPs online & 2296.794 & 2.951 & .087 \\
\hline & $\begin{array}{c}\text { Highest Educational Qualification } \\
*_{\text {webinars/workshops/conferences/FDPs online }}\end{array}$ & 2011.286 & 2.584 & .077 \\
\hline \multirow[t]{3}{*}{ F1 } & Highest Educational Qualification & 24.702 & 1.356 & .259 \\
\hline & webinars/workshops/conferences/FDPs online & 30.332 & 1.665 & .198 \\
\hline & $\begin{array}{c}\text { Highest Educational Qualification } \\
\text { *webinars/workshops/conferences/FDPs online }^{\text {*ars }}\end{array}$ & 5.902 & .324 & .723 \\
\hline \multirow[t]{3}{*}{ F2 } & Highest Educational Qualification & 124.024 & 2.100 & .124 \\
\hline & webinars/workshops/conferences/FDPs online & 197.565 & 3.345 & .068 \\
\hline & $\begin{array}{c}\text { Highest Educational Qualification } \\
*_{\text {*webinars/workshops/conferences/FDPs online }}\end{array}$ & 127.472 & 2.158 & .117 \\
\hline \multirow[t]{3}{*}{ F3 } & Highest Educational Qualification & 62.030 & 3.519 & .031 \\
\hline & webinars/workshops/conferences/FDPs online & 54.405 & 3.087 & .080 \\
\hline & $\begin{array}{c}\text { Highest Educational Qualification * } \\
\text { webinars/workshops/conferences/FDPs online }\end{array}$ & 70.208 & 3.983 & .020 \\
\hline \multirow[t]{3}{*}{ F4 } & Highest Educational Qualification & 48.970 & 2.866 & .058 \\
\hline & webinars/workshops/conferences/FDPs online & 44.610 & 2.611 & .107 \\
\hline & $\begin{array}{l}\text { Highest Educational Qualification } \\
\text { *webinars/workshops/conferences/FDPs online }^{\text {*ars }}\end{array}$ & 22.195 & 1.299 & .274 \\
\hline \multirow[t]{3}{*}{ F5 } & Highest Educational Qualification & 108.731 & 4.271 & .015 \\
\hline & webinars/workshops/conferences/FDPs online & 40.154 & 1.577 & .210 \\
\hline & $\begin{array}{c}\text { Highest Educational Qualification } \\
*_{\text {webinars/workshops/conferences/FDPs online }}\end{array}$ & 77.212 & 3.033 & .050 \\
\hline \multirow[t]{3}{*}{ F6 } & Highest Educational Qualification & 184.008 & 3.176 & .043 \\
\hline & webinars/workshops/conferences/FDPs online & 63.520 & 1.096 & .296 \\
\hline & $\begin{array}{c}\text { Highest Educational Qualification } \\
*_{\text {*webinars/workshops/conferences/FDPs online }}\end{array}$ & 99.245 & 1.713 & .182 \\
\hline
\end{tabular}

(BL= Blended Learning, F1= Learning Flexibility, F2= Online Learning, F3= Study Management, F4= Technology, F5= Classroom Learning and F6= Online Interaction) 
A two-way ANOVA was conducted that examined the effect of highest educational qualification of teachers and teachers who have attended/conducted webinars/workshops/conferences/FDPs online or not during COVID-19 pandemic on their attitude towards blended learning and its six dimensions as an approach for teaching-learning post-pandemic. There was a statistically significant interaction between the effects of highest educational qualification of teachers and teachers who have attended/conducted webinars/workshops/conferences/FDPs online or not on their attitude towards Study Management dimension of blended learning, $F=3.983, p=.020$. The plot of the mean "attitude towards study management dimension of blended learning" score for each combination of groups of "highest educational qualification of teachers" and "teachers who have conducted/attended webinars/workshops/conferences/FDPs online or not " are plotted in a line graph, as shown below in figure 6.

Also, there was a statistically significant interaction between the effects of highest educational qualification of teachers and teachers who have attended/conducted webinars/workshops/conferences/FDPs online or not on their attitude towards Classroom Learning dimension of blended learning, $F=3.033, p=.050$. The plot of the mean "attitude towards classroom learning dimension of blended learning" score for each combination of groups of "highest educational qualification of teachers" and "teachers who have conducted/attended webinars/workshops/conferences/FDPs online or not " are plotted in a line graph, as shown below in figure 7.

\section{Discussion And Conclusion}

The results from the discussed study shows that both Male and Female in-service teachers and also those teachers who have attended/ conducted webinars/ workshops/ conferences/ FDPs online or not did not differ in their attitude towards blended learning. But when the interaction effect between gender and teachers who have attended/conducted webinars/workshops/conferences/FDPs online or not was considered, the attitude of teachers varied significantly towards blended learning and online learning dimension of blended learning. This could be because in a regular Indian household, the time to explore new things is comparatively more with men than that with women of the house. Also, the experience that a learner gets while exploring the online platforms either by conducting or attending webinars/ workshops/ conferences/ FDPs helps in developing a positive attitude towards adopting a blended learning approach as the new in teaching-learning process. The fact cannot be ignored and is also reflected in the findings that attending and conducting webinars / workshops/ conferences/ FDPs has a significant effect on the online learning dimension of blended learning. The second part of the study implied that there was a statistically significant interaction between the effects of highest educational qualification of teachers and teachers who have attended/conducted webinars/workshops/conferences/FDPs online or not on their attitude towards Study Management dimension of blended learning. Teachers with higher degrees had a better attitude towards the adaptation towards blended learning. It is often seen that pursuing higher degrees (M.Phil/ Ph.D.) exposes an individual towards more e-learning resources. They end up exploring more during their research and 
development and hence adapting to new technological fronts becomes easier. Along with this, a statistically significant interaction between the effects of highest educational qualification of teachers and teachers who have attended/conducted webinars/workshops/conferences/FDPs online or not on their attitude towards 'Classroom Learning' dimension of blended learning. Again, the result showed that with a Doctorate degree, there is a positive change in the attitude towards blended learning.

\section{Declarations}

- $\quad$ Competing interests:

The authors declare that they have no competing interests.

\section{- $\quad$ Authors' contributions:}

RS identified the tool and PM made the online form for collecting data. Both RS and PM have distributed tool for data collection. PM did data sorting and RS did data analysis. RS and PM have collaboratively drafted the manuscript.

- $\quad$ Acknowledgements.

Not applicable

\section{- $\quad$ Authors' information:}

RS holds a Ph.D. in Education and is a teacher educator engaged in training aspiring teachers in the metropolitan city of Mumbai. RS is affiliated with the full time as well as distance education institutions with an experience of over 5 years.

PM is a Computer Scientist and an educationalist working in the field of Education for a premium Distance and Open Learning institution with an experience of over 11 years. She has knowledge and skills of two fields (Computer Science and Education) and is a Teacher Educator for aspiring Teacher Educators.

\section{- Disclosure of potential conflicts of interest}

The authors state that there are no conflicts of interest.

- Research involving human participants and/or animals

This article does not contain any studies involving animals performed by any of the authors.

\section{- Informed consent}

Informed consent was obtained from all individual human participants involved in the study. 


\section{References}

Arbaugh, J.B. \& Hwang, Alvin (2012). Uses of Multivariate Analytical Techniques in Online and Blended Business Education: An Assessment of Current Practice and Recommendations for Future Research. Journal of Management Education.

Birbal, R., Ramdas, M., and Harripaul, C. (2018, June). Student Teachers' Attitudes towards Blended Learning. Journal of Education and Human Development, 7(2), 9-26. doi:10.15640/jehd.v7n2a2

Dziuban, Charles D., Hartman, Joel L., \&Moskal Patsy D. Educause Centre for Applied Research. (Volume 2004 Issue 7, pp.3)

Fisk, P. (2017). Education 4.0 ... the future of learning will be dramatically different, in school and throughout life.

Friesen M. Report: Defining Blended Learning. Available at:

http://blogs.ubc.canfriesen/2012/09/01/where-does-blended-endvirtual-begin/

Hirata, Yoko, \& Hirata, Yoshihiro (2008). Japanese Students' Attitudes towards Hybrid Learning. Hybrid Learning and Education,

Hussin, Anealka Aziz, 2018, Education 4.0 Made Simple: Ideas for Teaching, International Journal of Education and Literacy Studies, v6 n3 p92-98.

International Labor Organization June 2020, https://www.ilo.org/wcmsp5/groups/public/--ed_dialogue/-sector/documents/briefingnote/wcms_742025.pdf

Kaur, Kuldip \& ZorainiWati , Abas (2004). An assessment of e-learning readiness at Open University Malaysia. International Conference on Computers in Education, 2004.

Kistow, Balraj (2011). Blended learning in higher education: A study of a graduate school of business. Trinidad and Tobago, Caribbean Teaching Scholar, Vol. 1, No. 2, November 2011, 115-128.

MHRD, NEP 2020, https://www.mhrd.gov.in/nep-new

Popovich, C. J., \& Neel, R. E. (2005). Characteristics of distance education programs at accredited business schools. American Journal of Distance Education, 19, 229-240

Procter C.T. Blended Learning in Practice, 2016.

Raturi, Shikha, Hogan, Robert \& Konai Helu Thaman (2014). Learners' access to tools and experience with technology at the University of the South Pacific: Readiness for e-learning. Australasian Journal of Educational Technology, 2011, 27(3), 411-427 
Rhona, Sharpe, et al. (October 2006). The undergraduate experience of blended e-learning: a review of UK literature and practice. The Higher Education Academy. (pp. 3)

Simon Stebbings, Nasser Bagheri, Kellie Perrie, Phil Blyth and Jenny McDonald (2012). Blended learning and curriculum renewal across three medical schools: The rheumatology module at the University of Otago, Australasian Journal of Educational Technology, 2012, 28(7), 1176-1189

Tolks, D., Pelczar, I., Bauer, D., Brendel, T., Gorlitz, A., Kufner, J., Simonsohn, A., \& Hege, I. (2014). Implementation of a Blended-Learning Course as Part of Faculty Development. Creative Education, 5, 948-953

\section{Figures}

\section{Figure 1}

Sample Size of Present Study based on Gender 


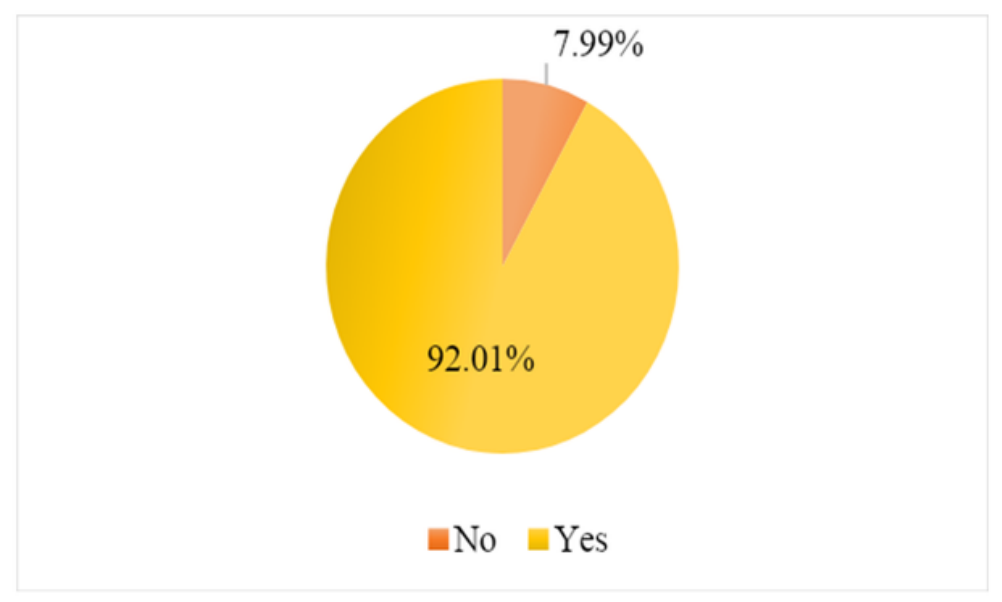

\section{Figure 2}

Sample Size of Present Study based on teachers who have conducted/ attended Webinars/workshops/conferences/FDPs online or not during COVID-19 Pandemic

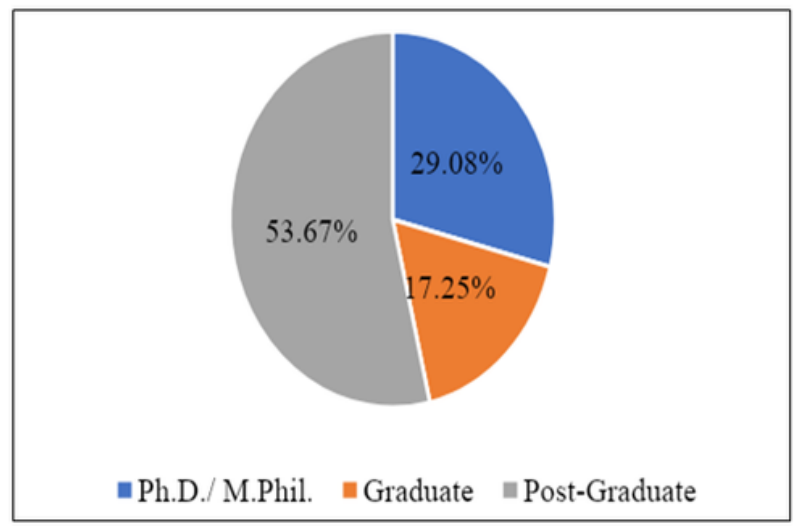


Figure 3

Sample Size of Present Study based on Highest Educational Qualification of Teachers

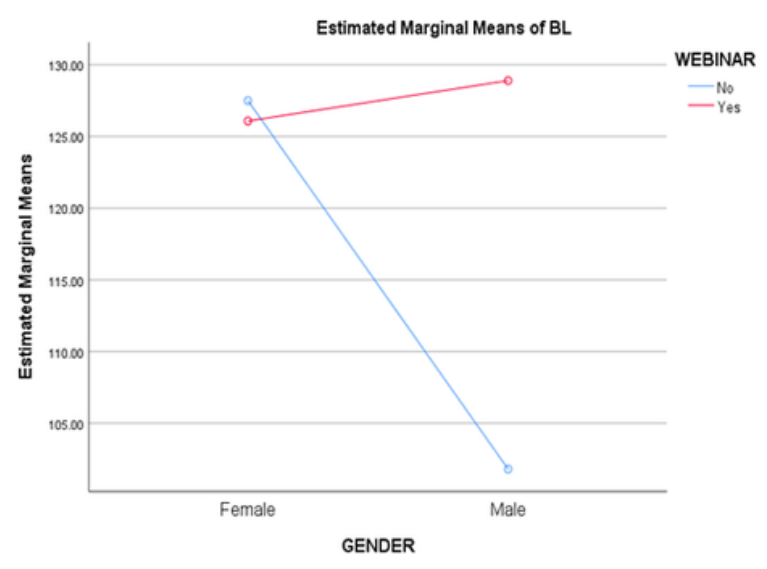

\section{Figure 4}

Interaction effect of gender and teachers who have conducted/attended webinars/workshops/conferences/FDPs online or not during COVID-19 era on BL 


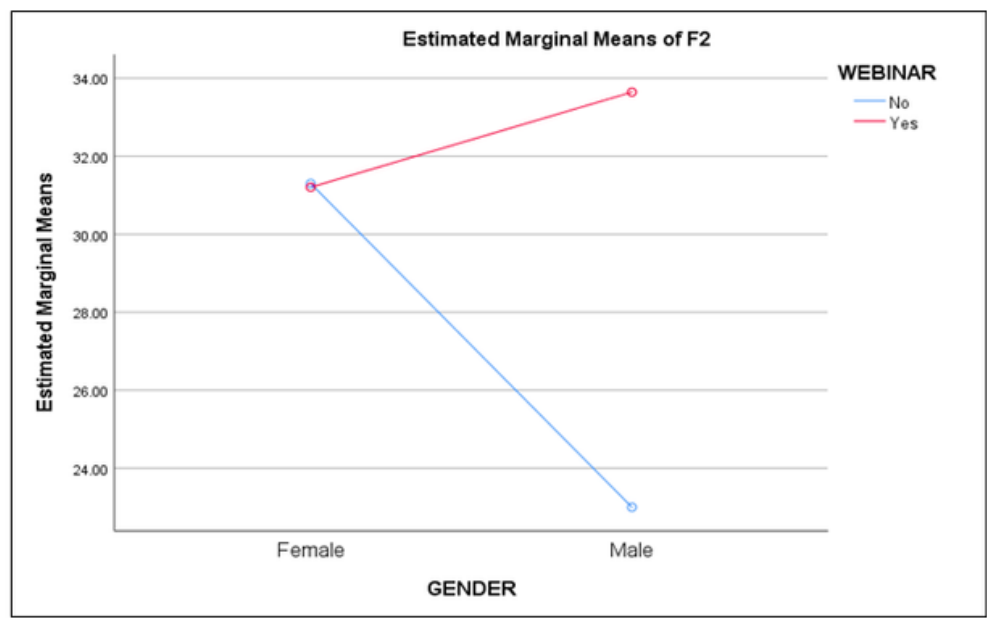

\section{Figure 5}

Interaction effect of gender and teachers who have conducted/attended webinars/workshops/conferences/FDPs online or not during COVID-19 era on F2 (Online Learning)

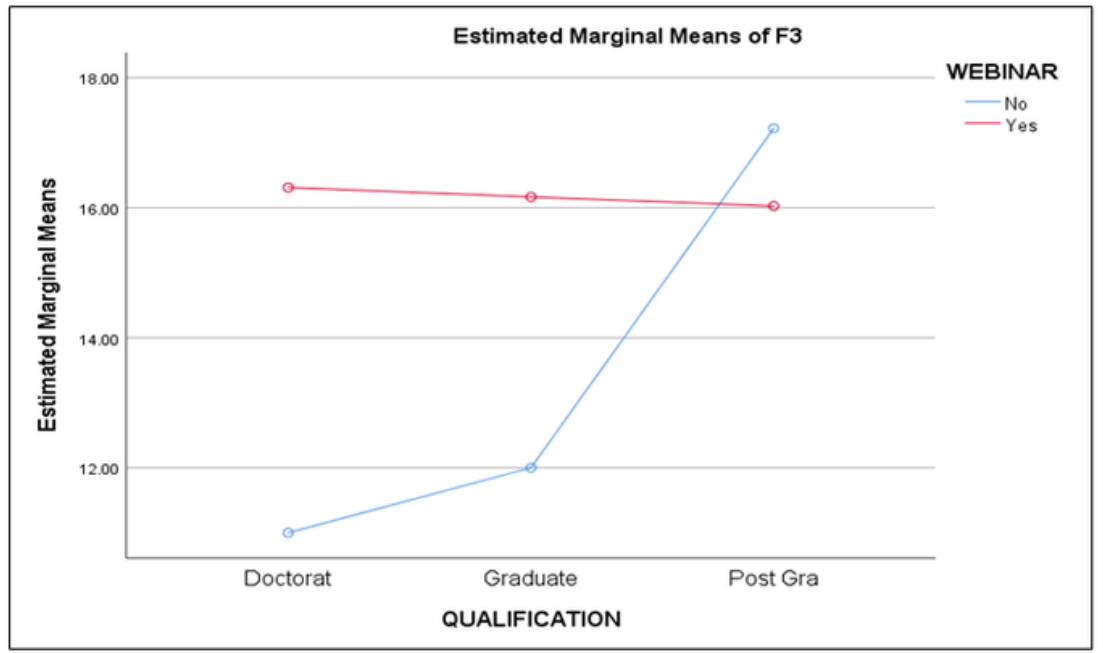


Figure 6

Interaction effect of Highest Educational Qualification of teachers and teachers who have conducted/attended webinars/workshops/conferences/FDPs online or not during COVID-19 era on F3 (Study Management)

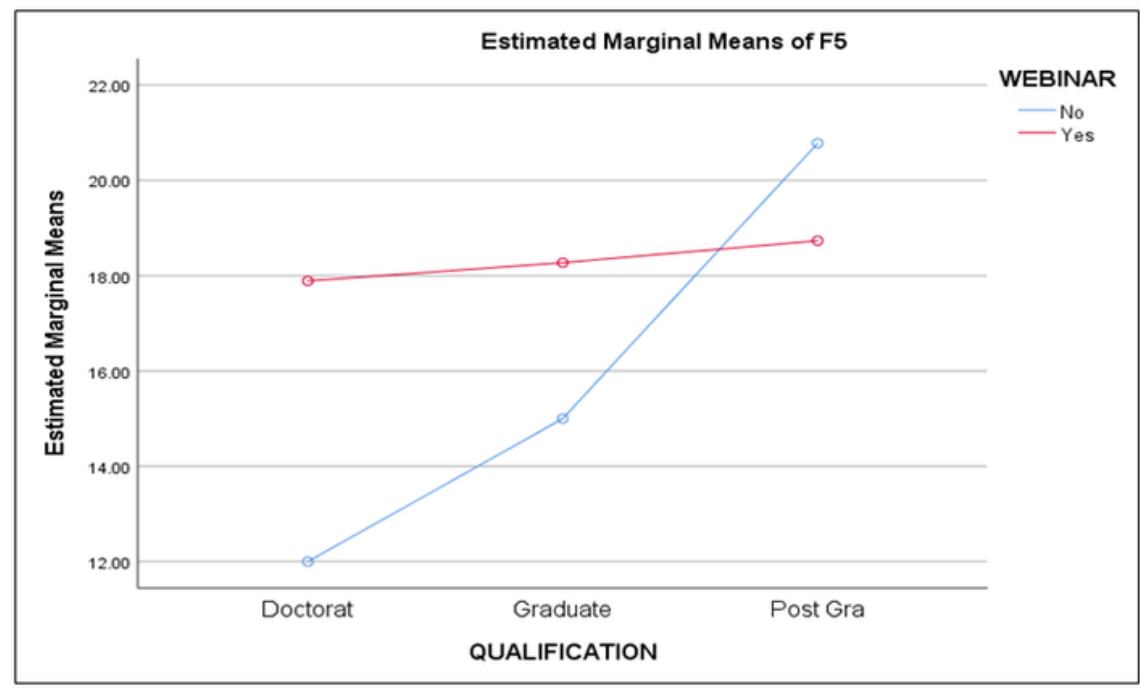

Figure 7

Interaction effect of Highest Educational Qualification of teachers and teachers who have conducted/attended webinars/workshops/conferences/FDPs online or not during COVID-19 era on F5 (Classroom Learning) 